\title{
Reductive Amination with a Scavenger: The Most "Combinatorial" of Two-Component Reactions
}

\author{
N. V. Ivanova, N. V. Tkach, E. N. Belykh, I. V. Dlinnykh, and E. V. Babaev \\ Lomonosov Moscow State University, Vorob'evy Gory 1, Moscow, 119991 Russia \\ e-mail: babaev@org.chem.msu.ru
}

Received July 10, 2009

\begin{abstract}
Synthesis of amine libraries from aldehydes via the liquid-phase parallel reductive amination with a simple scavenger (a Dowex resin) is described. Three parallel protocols are compared: reactions in well plates, SynCore apparatus, glass vials (without specific equipment). The presented detailed protocols can be useful for practical training of students.
\end{abstract}

DOI: $10.1134 / \mathrm{S} 1070363210120285$

\section{INTRODUCTION}

Reactions of liquid-phase parallel synthesis are subject to quite stringent requirements by quite different criteria. Collections of starting reagents should be cheap and diverse, reaction conditions should be simple and mild, and the products should be obtained in high yields and without complicated purification. For biological tests, the final molecule should contain a predeterminedly "pharmacophore" fragment. Many reactions fail to meet such criteria; for example, certain $\mathrm{C}-\mathrm{C}$ bond formation reactions can a priori be considered unsuitable (Diels-Alder reactions and even condensations produce a lot of admixtures, cross coupling makes use of hardly accessible reagents, etc.). Much more suitable are reactions involving nucleophilic nitrogen atom (formation of amides, sulfamides, hydrazides, or hydrazones), the best of which is formation of compounds with an aminoalkyl group.

Substituted aminoalkyl group $\left(\mathrm{NHRCH}_{2-}\right.$ or $\mathrm{NR}_{2} \mathrm{CH}_{2}-$ ) is a well-known pharmacophore group in a great variety of medicines and natural compounds. There are several strategies for introducing this group into a desired substrate: Mannich reaction (1), Nalkylation (2), and reductive amination (3).

The first two reactions have natural limitations, since not every substrate can be introduced into the Mannich reaction, and not any combination of amine and alkylating agent results in unambiguous mono-

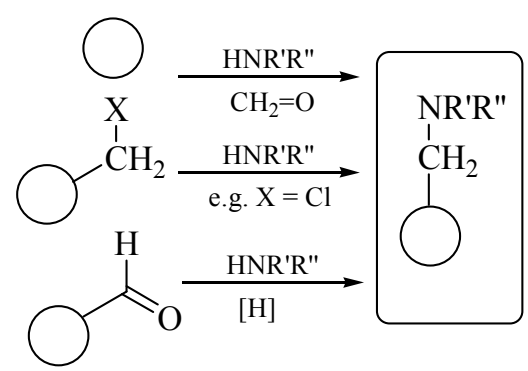

alkylation. The third strategy (conversion of carbonyl group into aminoalkyl) is the only which is practically universal in nature, as reflected in detail in a series of reviews [1-4]. The popularity of this reaction is largely associated with the wide distribution and accessibility of aldehydes, since there are numerous ways to introduce aldehyde group into a great variety of substrates. The key feature of reaction (3) is that it involves intermediate formation of imines (Schiff bases).

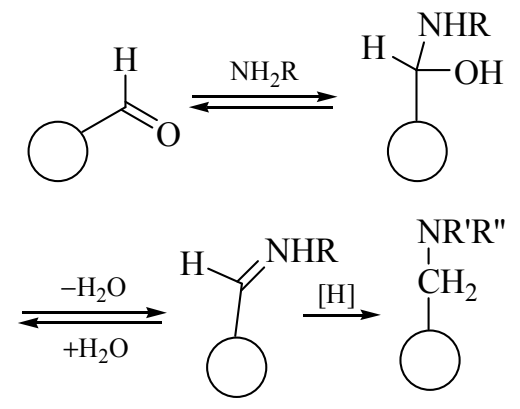

This stage is reversible. Provided imine has been selectively reduced into amine (in the presence of aldehyde), the reaction can be brought to completion to obtain the final amine in high yield. In the reaction of 
aldehydes with secondary amines, reduction is experienced by the equilibrially formed iminium salt. The problem is to properly choose a selective reducer which fast reacts with imine and not reacting (or slowly reacting) with aldehyde [5]. The best reagents [6] were found to be $\mathrm{Na}\left[\mathrm{BH}(\mathrm{OAc})_{3}\right]$ and $\mathrm{Na}\left[\mathrm{BH}_{3} \mathrm{CN}\right]$.

The standard admixtures in this reaction are traces of alcohol (side reduction of aldehyde), as well as unreacted starting materials. The reaction occurs under heterogeneous conditions in DCM or DCE, and efficient agitation of the heterogeneous mixture is the principal condition for complete reaction.

Products can be purified by using the simplest scavenger, specifically a Dowex ion-exchange resin. This resin is a styrene-divinylbenzene copolymer containing sulfonic acid groups which bond amines into salts. As a result, aldehyde is filtered throught the resin and removed with the filtrate. The amine bound by the cationite is expelled from the resin by another amine, say, diethylamine (in methanol). It is quite clear that the final product (amine 2) of the "aldehyde + amine $1=$ amine 2 " reaction cannot be purified from the starting reagent (amine 1) in this way, and the solution eluted from the resin necessitates further purification.

Having called the reductive amination reaction the most "combinatorial," we would like to focus on certain details of its implementation in the parallel mode. Such details are rarely described in scientific publications. At the same time, it is just in Russia that this reaction has received a great deal of attention. The reaction was one of the most popular objects at Moscow research laboratories of the ChemBridge company, as a result of which at the Global Market tens (if not hundreds) thousands of compounds for testing comprise just this structural motif. Owing to the facility for implementation, this reaction is convenient to use for teaching for the basic principles of liquidphase parallel synthesis: It does not require sophisticated equipment and can be used even at lowbudget training laboratories.

For this reason, the present paper is built as a training task (with protocols and instructions for students), as it was suggested to students of the Moscow State University (MSU) over many years. The task is given in three versions. The first version is the simplest and requires virtually no equipment. The second version is based on a real practice of the implementation of this work at ChemBridge laboratories, using quite interesting techniques. Finally, the third version represents the adaptation of this task to SynCore apparatus, performed at the MSU by the request of the producer company Buchi. This synthesis was highly appreciated by the Swiss company, and our procedures were included in the "Best at Buchi" booklet [7]. The reactions performed at the MSU by the simplest, first scheme (5) and subsequent in vivo tests resulted in the discovery of a new family of anxiolytics [8].

\section{Synthesis without Special Equipment}

The training reductive amination reaction (like the Ugi reaction [9]) is a facile and an illustrative example highlighting specific features of parallel organic synthesis. The suggested training task was perfected by a group of students during the special laboratory course in combinatorial chemistry at the MSU in 2002-2004. In its chemical essence, it is a one-stage reductive amination reaction between series of heterocyclic aldehydes and aliphatic amines, with $\mathrm{Na}\left[\mathrm{BH}(\mathrm{OAc})_{3}\right]$ as the reducer. The task involves the stage of parallel purification of products by means of the simplest scavenger, viz. an ion-exchange resin.

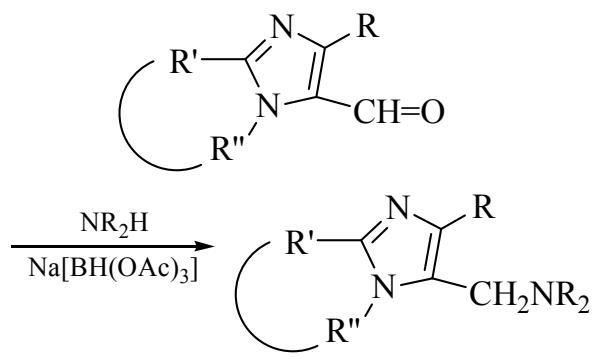

Each student performed six syntheses of four target compounds by reductive amination (1 aldehyde + 4 amines), and, therewith, in three cases the aldehydes/ amine molar ratio was varied). Over the course of six lessons (2-3 h each) each student performed six parallel reactions, preliminary purification of the reaction product on a Dowex cation exchanger, and chromatographic purification of products, after which their NMR were measured. At the final lesson students had to draw conclusion as to optimal reaction conditions and analyze the yields and purity of the products.

\section{Reagents and Solvents:}

(1) Dichloroethane (DCE), dichloromethane (DCM), isopropanol, potassium carbonate, anhydrous sodium sulfate, silica gel for chromatography, and Silufol plates; 
Scheme 1.

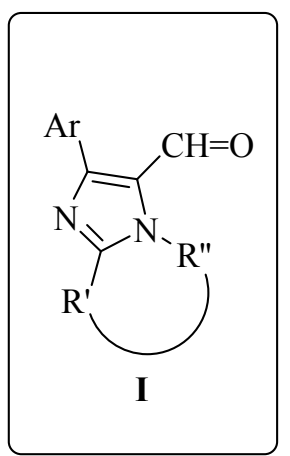

(a)

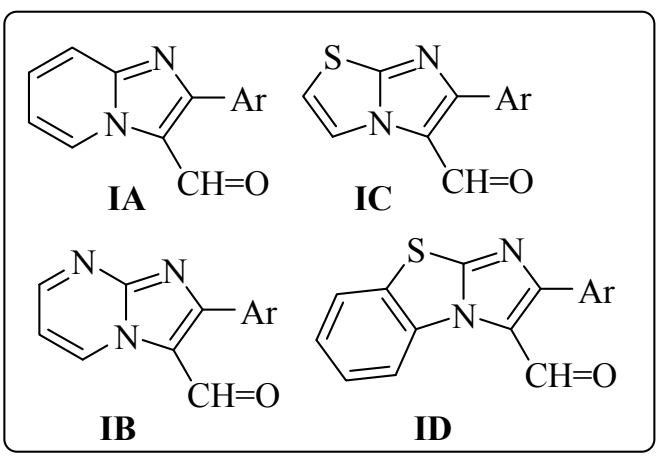

(b)

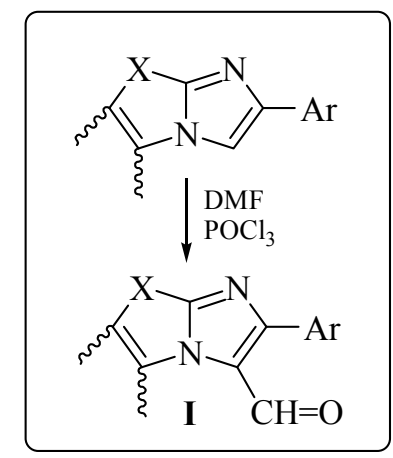

(c)

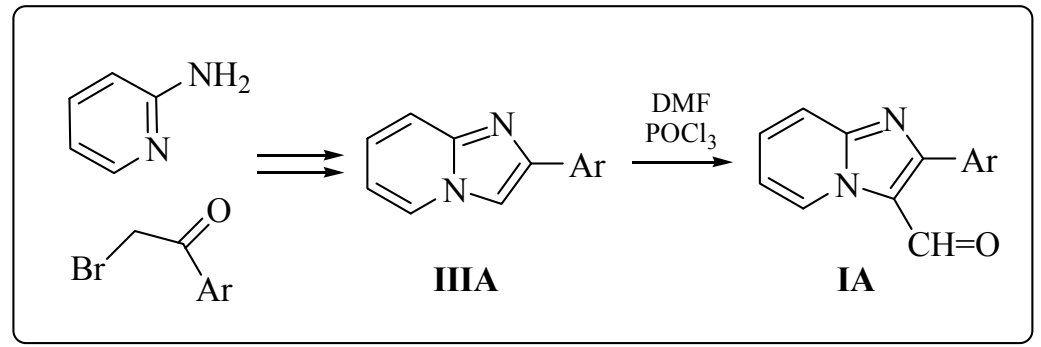

(d)

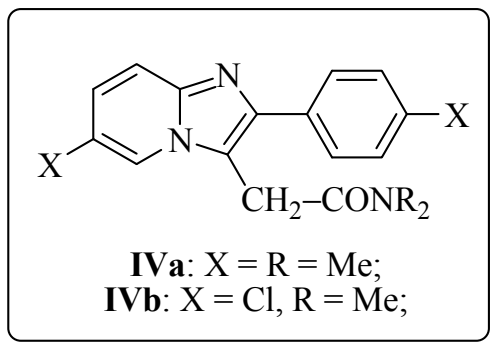

(e)
(2) $\mathrm{Na}\left[\mathrm{BH}(\mathrm{OAc})_{3}\right]$ as the reducer and anhydrous oxalic acid for precipitating oxalates;

(3) Dowex ion-exchange resin for purification of products from aldehydes admixtures;

(4) a series of 5-10 secondary aliphatic amines, for example, cyclic (pyrrolidine, piperidine, morpholine, etc.). We additionally used a series of amines on the basis of 4-substituted piperazines (4-alkyl and 4-acyl derivatives) and piperidine-4-carboxamides (substituents in such amines can be readily varied, provided 1-Bocpiperazine or $N$-Boc-isonipecotic acids are available in sufficient amounts);

(5) a series of 5-10 aromatic aldehydes. We used a specific set of heterocyclic aldehydes of the imidazole series of general formula $\mathbf{I}$, in which $\mathrm{R}^{\prime}$ and $\mathrm{R}^{\prime \prime}$ form a different heteroring (Scheme 1): pyridine (IA), pyrimidine (IB), thiazole (IC), or benzothiazole (ID). Such aldehydes I are can be easily prepared by the Wilsmeyer reaction by formylation of the corresponding condensed imidazoles III (Scheme 1c).

The starting bridged heterocycles III are quite easily prepared by the classical Chichibabin scheme from aminoheterocycles and phenacyl bromides (the example for subclass IIIA is given in Scheme 1d). The yields at all the stages are fairly high, and the procedures for synthesis of aldehydes I [10] and their precursors III [11] can be found in the literature.

As a result, the short synthetic sequence leading to aldehydes I allows flexible variation of the heterocyclic and aryl residues in the aldehyde, and compounds II formed by the reductive amination reaction are structurally definitely related (drug likeness) to known drugs IVa (zolpidem) and IVb (alpidem) (Scheme 1e).

\section{Equipment:}

(1) a set of automatic one-channel pipettes of various volumes with a set of tips for them;

(2) a set of glass vials with screw caps (three times the number of reactions) and any shaker for agitation;

(3) a set of plastic syringes with a porous diaphragm (Fig. 1) for passing reaction mixtures through the cation-exchange resin. Syringes can also be used as mini-columns for chromatography, but it is better to pass the mixtures through a short silica bed on a glass filter. One should think out thoroughly how to fix, in a convenient and space-saving way, six syringes (filters) at one workplace; for example, a simple metal manifold can be used (Fig. 1);

(4) standard glassware with a great number of glasses $(60-100 \mathrm{ml})$. 


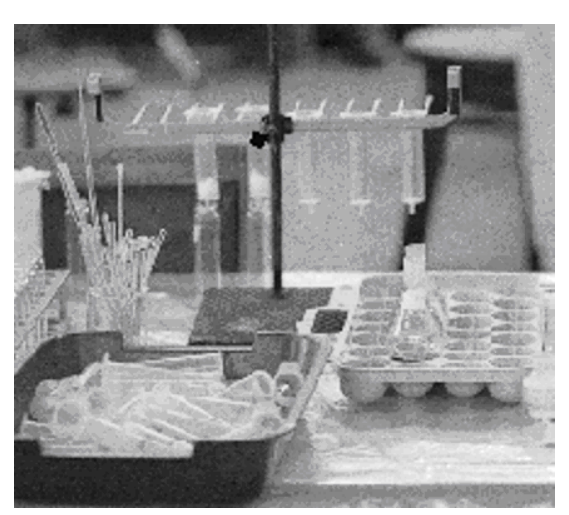

Fig. 1. Space-saving fastening of syringe columns in a manifold.

\section{Acquired Skills}

At the lessons students get familiar with details of the reductive amination reactions and optimize its conditions, master techniques in parallel synthesis, purification, and in working with scavengers. To get familiar with the technological aspects of parallel synthesis, it is useful to repeat the same task in the plate mode.

\section{Lesson 1. Reagent loading.}

The students get a variant of the task to obtain four target compounds by the reductive amination reaction. The requirement is to obtain three target compounds in similar conditions ( 1 aldehyde plus 3 amines) and one target compound at varied reagent ratios (the same aldehydes plus the fourth amine in 1.2:1, 1:1, and 1:2 ratios). An example possible reagent loading is shown in Table 1.

The teacher explains that in this case (variant F) one and the same aldehydes 5 of the aldehydes set (code CO5) is used in all experiments, and it is reacted with four amines (codes который NR09- NR12). Solutions of aldehydes and amines are prepared and enumerated in advance, and, therefore, students fulfill the following simple operations.

(1) Stick labels on each vial, according to the variant obtained. For example, $1 \mathrm{~F}, 2 \mathrm{~F}, 3 \mathrm{~F}, 4 \mathrm{~F}, 5 \mathrm{~F}, 6 \mathrm{~F}$ ( $\mathrm{F}$ is task variant and the figure is experiment number).

(2) A $0.343 \mathrm{M}$ solution of aldehydes in DCE $(2 \mathrm{ml})$ is added to each vial with a pipette or, with poorly soluble aldehydes, $2 \mathrm{ml}$ of DCE is added to a weighed sample corresponding to $0.69 \mathrm{mmol}$ of aldehyde.

(3) A DCE solution of required amine is transferred to each vial. The solutions are prepared in advance.

In experiment nos. 1-4, add each amine solution $(1.66 \mathrm{ml})$ to each vial (aldehyde:amine 1.2:1). In experiment no. 5 , add $2 \mathrm{ml}$ of a solution of the fourth amine to aldehyde solution (aldehyde:amine 1:1). In experiment no. 6 , add $4 \mathrm{ml}$ of a solution of the fourth amine to aldehyde solution (aldehyde:amine 1:2).

Close the vials with screw caps and place into a shaker for agitation.

It is recommended to finish the lesson at this stage, since to reach equilibrium between the reagents with intermediate imine formation takes some time. The best results are obtained if the reducer is added in 12$24 \mathrm{~h}$.

\section{Lesson 2. Imine reduction.}

(4) Add $2 \mathrm{ml}$ of a suspension of a DCM solution of $\left\{\mathrm{Na}\left[\mathrm{BH}(\mathrm{OAc})_{3}\right]\right\}$ to each vial with a pipette. Screw the vials with caps untightly (hydrogen is evolved) and place into the shaker. The reaction is usually complete in $24-48 \mathrm{~h}$.

\section{Lesson 3. Isolation of the target product.}

(5) Add $10 \mathrm{ml}$ of $20 \%$ aqueous potassium carbonate to each vial. Screw the vials with caps untightly and agitate in the shaker for $30 \mathrm{~min}$.

Reagent codes and amounts and product codes in variant $\mathrm{F}$

\begin{tabular}{|c|c|c|c|c|c|}
\hline \multirow{2}{*}{ Exp. no. } & \multicolumn{2}{|c|}{ Reagent codes } & \multicolumn{2}{|c|}{ Reagent amounts } & \multirow{2}{*}{ Product codes } \\
\hline & aldehyde & amine & aldehyde, ml & amine, $\mathrm{ml}$ & \\
\hline $1 \mathrm{~F}$ & $\mathrm{CO}_{5}$ & NR09 & 2.0 & 1.66 & $1 \mathrm{~F}-\mathrm{CO}_{5}-\mathrm{NR} 09$ \\
\hline $2 \mathrm{~F}$ & $\mathrm{CO}_{5}$ & NR10 & 2.0 & 1.66 & $2 \mathrm{~F}-\mathrm{CO}_{5}-\mathrm{NR} 10$ \\
\hline $3 F$ & $\mathrm{CO}_{5}$ & NR11 & 2.0 & 1.66 & $3 \mathrm{~F}-\mathrm{CO}_{5}-\mathrm{NR} 11$ \\
\hline $4 \mathrm{~F}$ & $\mathrm{CO}_{5}$ & NR12 & 2.0 & 1.66 & $4 \mathrm{~F}-\mathrm{CO}_{5}-\mathrm{NR} 12$ \\
\hline $5 \mathrm{~F}$ & $\mathrm{CO}_{5}$ & NR12 & 2.0 & 2.0 & $5 \mathrm{~F}-\mathrm{CO}_{5}-\mathrm{NR} 12$ \\
\hline $6 \mathrm{~F}$ & $\mathrm{CO}_{5}$ & NR12 & 2.0 & 4.0 & $6 \mathrm{~F}-\mathrm{CO}_{5}-\mathrm{NR} 12$ \\
\hline
\end{tabular}


(6) Prepare six empty vials with the same labels as on the reaction vials. Withdraw from each reaction vial with a syringe the lower (organic) layer and transfer into the empty vial. Extract the aqueous layer once with $5 \mathrm{ml}$ of DCM. Combine the organic layers.

(7) Perform TLC of the organic layer, using as references the starting aldehydes and amine (eluent $\mathrm{CHCl}_{3} / \mathrm{MeOH}, 8: 1$ or $\mathrm{C}_{6} \mathrm{H}_{6} / \mathrm{EtOAc}, 2: 1$ ). It is recommended to apply on the first plate three first reaction mixtures plus three starting amines and aldehyde and on the second plate, the other three reaction mixtures plus the fourth starting amine, and aldehyde.

(8a) If no starting aldehyde is observed in the chromatograms, add to the solutions anhydrous $\mathrm{Na}_{2} \mathrm{SO}_{4}$ as a drying agent. Screw the vials with caps and leave overnight.

\section{Lesson 4. Product purification.}

(8b) If the starting aldehyde is still observed, further purification should be performed. The first method: Shake the organic layer with aqueous sodium bisulfate and repeat TLC. The second method: Apply the organic layer on a column (Fig. 2) packed with Dowex saturated with pyridine. The resin well absorbs the product but poorly adsorbs the starting aldehyde. Wash the column with methanol until the eluate no longer contains traces of aldehyde. Elute the final product with methanolic diethylamine. Evaporate the methanolic solution under a hood. Additional purification requires chromatography (see item 9).

(9) When the starting aldehyde is no longer present, but the starting amine is still present, chromatographic purification on silica (eluent $\mathrm{CHCl}_{3} / \mathrm{MeOH}, 8: 1$ ) is required. As a rule, the starting aliphatic amine have low $R_{f}$, and, therefore, it is readily separated by passing the mixture through a short silica bed on a glass filter.

(10) The final reductive amination products (after chromatographic purification) can be additionally purified by their precipitation as oxalates. To this end, add a solution of oxalic acid in isopropanol to product solutions and leave until precipitates form.

Lessons 5 and 6. Filtration of precipitates and determination of product yields.

(11) Filter off the oxalate precipitates, wash with ether, and dry.

(12) Stick labels with codes on the vials, for example, 1F-CO5-NR12, where $1 \mathrm{~F}$ is the experiment number; $\mathrm{CO}_{5}$, aldehyde number, and NR12, amine
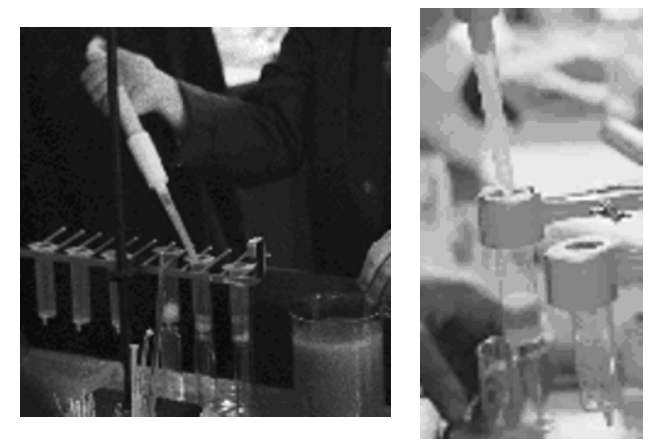

Fig. 2. Loading a suspension of an ion-exchange resin into columns with a dispenser and subsequent washing of the columns.

number (Table 1). Weigh empty vials, determined the weight of products, and calculate the yields. Prepare one of the samples for ${ }^{1} \mathrm{H}$ NMR measurements.

At the final lesson, the results of study of the effect of reagent ratio on product purity and yield are discussed. As a rule, the conversion rises if one of the reagents is present in excess, but you should "pay" for that by the necessity to remove excess aldehyde (scavenger) or amine (chromatography).

\section{Technology of Microsynthesis in Plates}

To prepare large libraries of compounds by liquidphase parallel synthesis, special technologies and equipment are required. Such equipment is usually available in companies specializing on combinatorial synthesis. After fulfilling the previous task at the training laboratory of the MSU, for students who desired to master the modern technology of parallel liquid-phase microsynthesis in plates, three 3-h lessons in the laboratory of the ChemBridge company in Moscow were organized. As substrates, the same heterocyclic aldehydes as in the MSU were used, while the range of amines was essentially extended.

Ten students took part in these lessons. In the ChemBridge laboratory each student accomplished in a rack 48 reductive amination reactions ( 1 aldehyde with 48 amines). A total of 332 products were obtained. The following procedure is a protocol for fulfilling this task.

\section{Practical Implementation of the Work}

There are a number of simple techniques to facilitate liquid-phase parallel synthesis. First, metal block racks $(6 \times 8)$ for 48 tubes are used (Fig. 3). Reagents and solvents are added with multichannel 

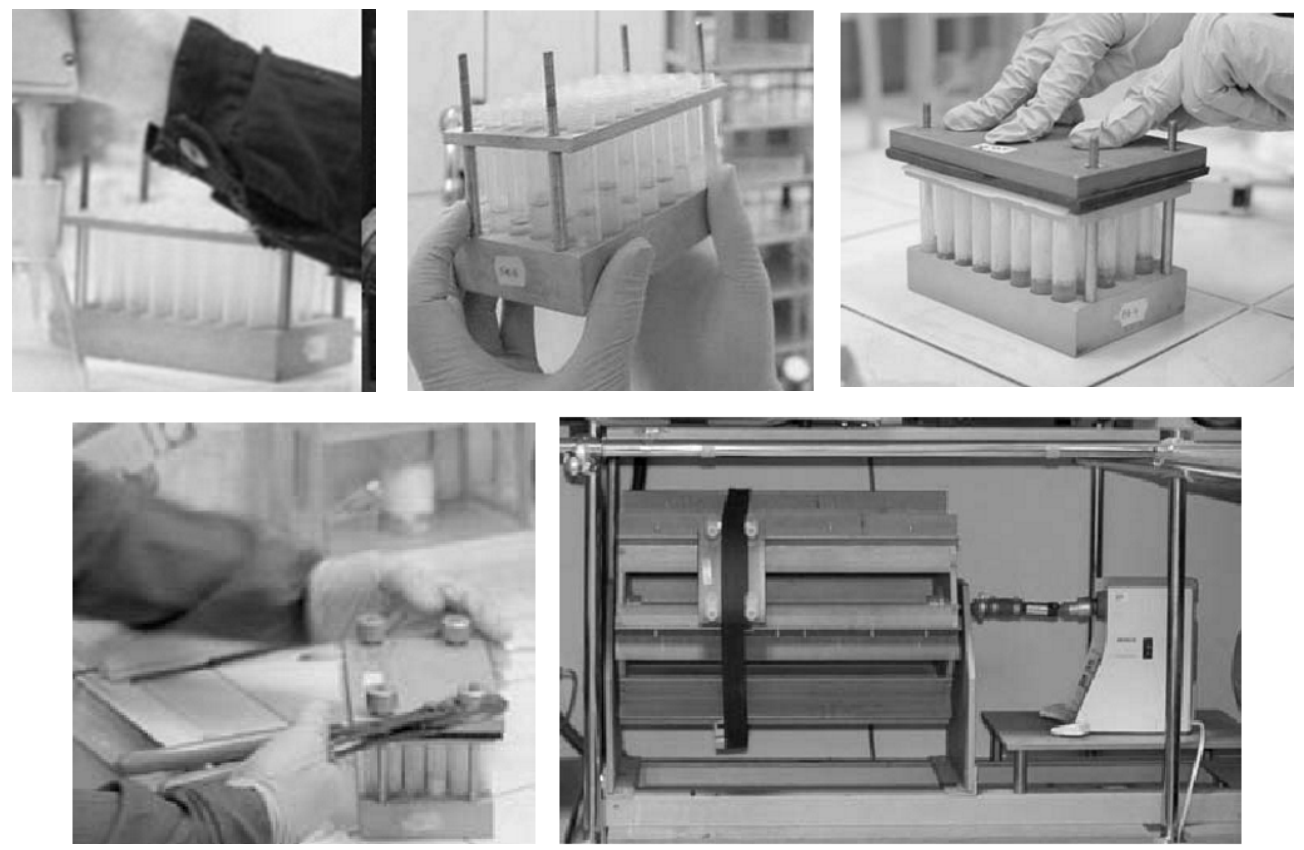

Fig. 3. Loading of starting reagents in the $6 \times 8$ format, hermetization of the plate, and parallel wahich of several plates.

pipettes ( 6 or 8 tips). The whole block is covered with a single Teflon seal, and the contact between the seal and tubes is improved by means of an additional metal screw top cover. Stirring is performed in a drum accommodating several blocks.

\section{Stage 1.}

A plate for 48 glass tubes $(6 \mathrm{ml})$ is charged with a suspension of finely ground $\mathrm{Na}\left[\mathrm{BH}(\mathrm{OAc})_{3}\right]$ in $\mathrm{DCM}$ $(800 \mu 1,3.6 \mathrm{mg}, 0.17 \mathrm{mmol}$ per tube; $3.6 \mathrm{~g} / 40 \mathrm{ml}$ $\mathrm{CH}_{2} \mathrm{Cl}_{2}$ per plate) by means of a Step-Pett dispenser.

Solutions of corresponding amines (by $0.2 \mathrm{mmol}$ ) and aldehydes (by $0.26 \mathrm{mmol}$ ) in DCM (by $400 \mu \mathrm{l}$ ) are added to the reducer. If a different loading sequence is used, make sure there is no contact between aldehydes and reducer during loading.

If a compound is poorly soluble, the solvent volume can be increased. Reagents are loaded with a $1000-\mu 1$ pipette with Matrix long tips $(1250 \mu 1)$. The tips are positioned in an order corresponding to the loading order in a special stand and further used at all stages of isolation of the given load, after which the tips are washed in lines by means of an 8-channel pipette).

The tubes are covered with a rectangular Teflon seal, fastened with an additional metal screw cover, and thoroughly mix in a grill-type drum for $24 \mathrm{~h}$. The solutions are reduced to $100 \mu \mathrm{l}$ in air or in a drying oven at $40^{\circ} \mathrm{C}$.

The next stage involves separation of the final amine from unreacted aldehyde in each reaction mixture. To this end, like in the previous task, the mixture is passed through a Dowex cation-exchange resin. When working with 48 mixtures on columns, it is hard to follow the sorption process for the whole array of samples.

\section{Stage 2.}

To remove aldehyde from the reaction mixtures, the solution residues obtained at the first stage, are dissolved in methanol and transferred with an 8channel pipette with 5-ml tips to columns loaded with $4 \mathrm{ml}$ of a Dowex-Py suspension. (The suspension is prepared by magnetically stirring $90 \mathrm{~g}$ of Dowex and $100 \mathrm{ml}$ of methanol, see Fig. 4a.). The suspension is applied on the column with an 8-channel syringe dispenser or a 40-ml step dispenser (Fig. 4b).

Further on neutral admixtures (aldehydes) are eluted with methanol ( $5 \mathrm{ml}$ per column) (Fig. $4 \mathrm{c})$. The first $5 \mathrm{ml}$ of the neutral layer are collected into 48 glass tubes $(6 \mathrm{ml})$; therewith, the possible breakthrough of amine is followed by TLC. If necessary, one more plate with resin columns is used, and the neutral layer 
is applied again. Methanol residues are pressed out from the columns with compressed air.

The final products are eluted with a $30 \%$ solution of diethylamine in methanol into 48 glass tubes $(6 \mathrm{ml})$ placed in two racks. Amine solutions should be poured into filtering columns as uniformly as possible so that all receivers are filled up to the top by the end of elution. If after addition of diethylamine the product starts to crystallize on the resin, the methanol/ diethylamine mixture (after the first $5-\mathrm{ml}$ portion) should be replaced by a $1: 1$ chloroform/methanol mixture.

At the next stage, it is necessary to remove completely the solvent and diethylamine (bp $56{ }^{\circ} \mathrm{C}$ ). To this end, a Savant vacuum centrifuge operated in the freeze-drying mode [12] is used. The centrifugal force prevents solvent bumping, and even fairly highboiling solvents like DMSO can be evaporated.

\section{Stage 3.}

The solvent is evaporated to dryness at $40^{\circ} \mathrm{C}$ in a Savant centrifuge for $6 \mathrm{~h}$, the products are dissolved in $200-400 \mu \mathrm{l}$ of chloroform, and analyze by TLC. The products which require no further purification are transferred into weighed plastic tubes $(6 \mathrm{ml})$, labeled with barcodes for electronic data reading. Therewith, $10 \%$ of each solution is taken for NMR measurements and transferred to a Marsh plate $(96 \times 1.2 \mathrm{ml})$. Both plates are labeled (positions of unlabeled tubes correspond to the loading list), the solvent is evaporated in air or in a drying oven at $40^{\circ} \mathrm{C}$, and removed completely in a vacuum drying oven. The loading list and chromatogram are archived.

If, according to TLC data, the products contain traces of the strating amine, they are dissolved in $300 \mu 1$ of chloroform and pass through chromatographic

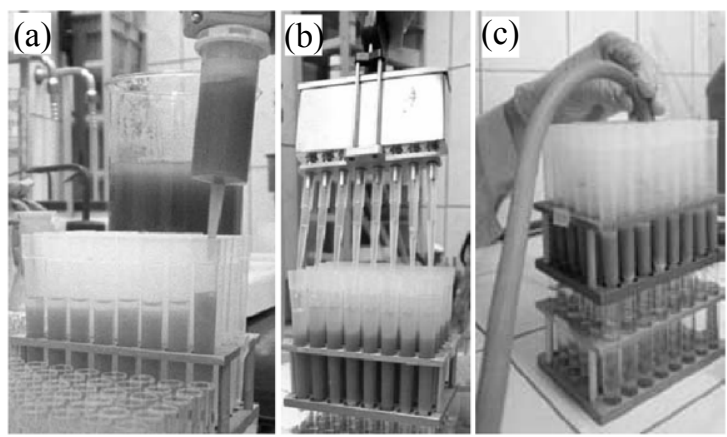

Fig. 4. Preliminary purification of 48 reaction mixtures on a Dowex cation-exchange resin. For denotations, see text.

columns. Filtration is performed using Oros membrane-bottom plates $(50 \mathrm{mg}$ of silica, which corresponds to the mark in the lower part of the column).

\section{Stage 4.}

Silica is charged with a well dispenser. To this end, silica is charged to a block with drilled-in holes and leveled for uniform distribution over holes (Fig. 5a). The holes are then superposed with wells (Fig. 5b), and the whole construction is turned upside down. As seen (Fig. 5c), the sorbent is uniformely distributed over 48 (or 96) plate wells.

Solutions are applied on columns with pipettes (Fig. 6a). Eluates are collected into 48 glass tubes (6 ml), silica is washed with chloroform (final volume of the eluate is $\sim 3 \mathrm{ml}$ ), and TLC analysis is performed. If necessary, the operation is repeated, after which the products are transferred into pre-weighed tubes.

The products requiring preparative column chromatography (admixtures having higher $\mathrm{R}_{\mathrm{f}}$ than the product), are collected separately for subsequent purification (Fig. 6b).

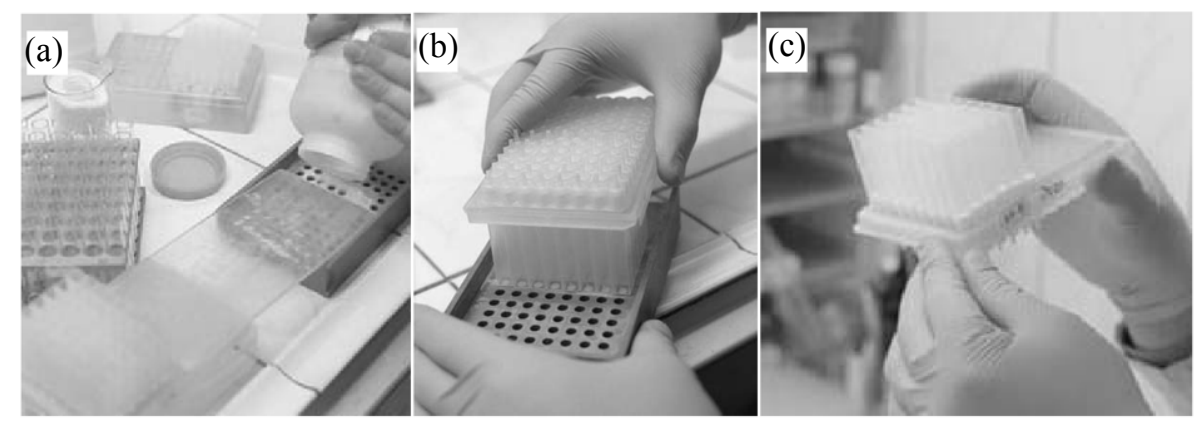

Fig. 5. Preparation of a plate for chromatographic separation of 48 compounds. For denotations, see text. 
(a)

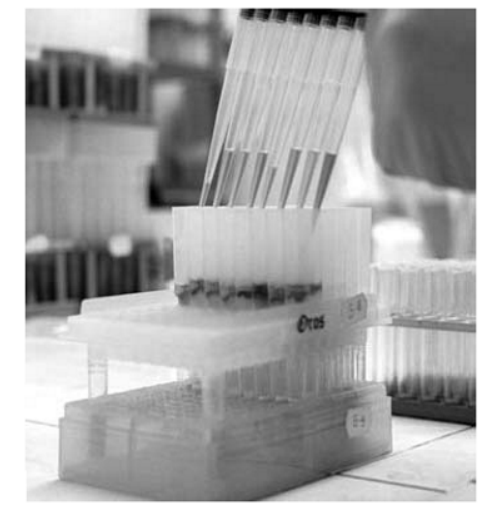

(b)

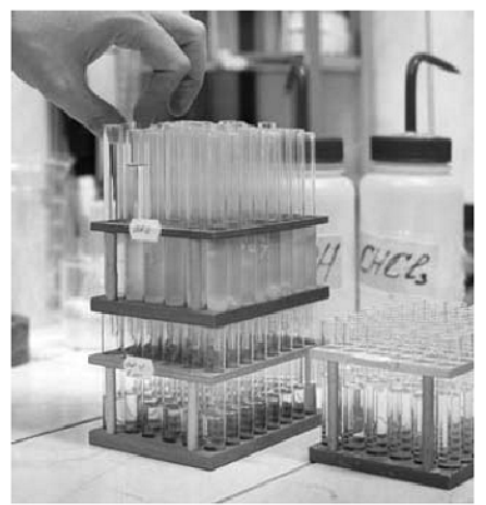

Fig. 6. Parallel chromatography of 48 compounds (format $6 \times 8$ ). For denotations, see text.

\section{Liquid-Phase Parallel Synthesis in SynCore Apparatus}

The next task was fulfilled using a SynCore apparatus for parallel synthesis. Our aim was to compare the work on a high-cost equipment with the previous techniques: a "usual" laboratory technique and microsynthesis in plates.

For the present task we took a different series of heterocyclic aldehydes IE. Students reacted 5-arylfurfurals IE with secondary cyclic amines [reaction (6)].<smiles>[R10]NCc1ccc([Al])o1</smiles>

The acidophobic and oxidation-sensitive furan ring is considered as an "inconvenient" fragment in parallel synthesis, since furans are more reactive, and, therefore, give more by-products. The subclass of 5-arylfurfurals are more stable compounds obtained by arylation of furfural. The arylating agents are unstable diazonium salts which are readily available from various anilines. Therefore, it is easy to prepare a fairly wide series of aldehydes IE.

There are rare examples of reductive amination of furfural and its aldehyde derivatives (including 5-aryl derivatives IE [13-15]), but this subject has not yet been studied systematically. Interestingly, the resulting compounds contain a furfurylamine fragment which is a structural fragment of many drugs (the most known of them is furosemide). Therefore, we could consider these compounds as drug-like molecules:<smiles>NS(=O)(=O)c1cc(C(=O)O)c(NCc2ccco2)cc1Cl</smiles>

Furosemide (diuretic)<smiles>CN(C)CCN(Cc1ccco1)c1ccccn1</smiles>

Metafurilene (antihystamine drug)<smiles>C/C=C(\NC)NCCSCc1ccc(CN(C)C)o1</smiles>

Ranitidine/Zantac

(stomach acid production inhibitor)

Reagents and Solvents:

(1) DCM, isopropanol, potassium carbonate, anhydrous sodium sulfate, silica gel for chromatography, Silufol plates;

(2) $\mathrm{Na}\left[\mathrm{BH}(\mathrm{OAc})_{3}\right]$ as the reducer and anhydrous oxalic acid for precipitating oxalates;

(3) a series of secondary cyclic aliphatic amines (from 3-6 to 20) and a series of 5-arylfurfurals (from 4 to 10). The set is selected so that all 24 vessels of the 
(a)

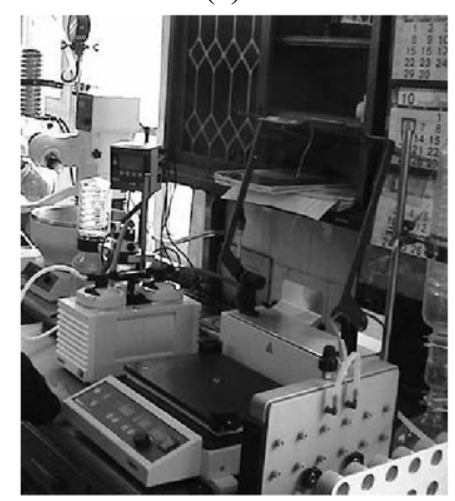

(c)

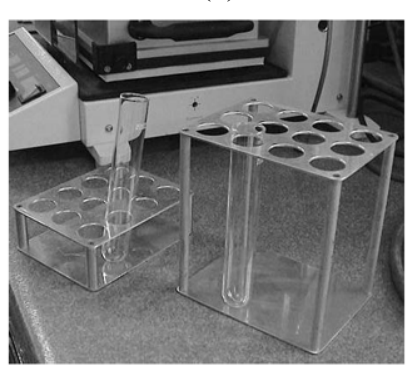

(b)

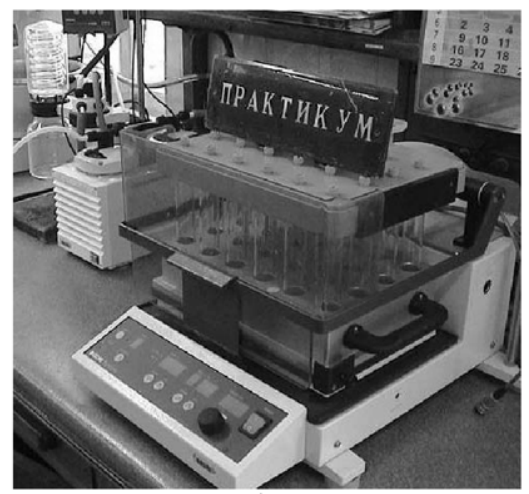

(e) (d)

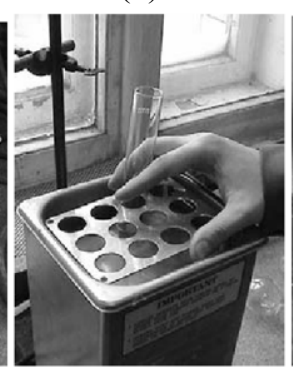

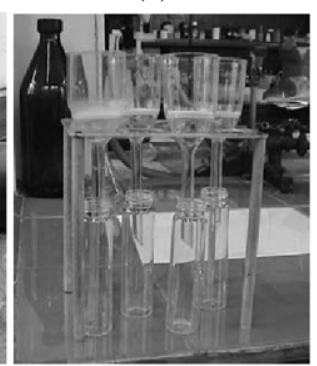

Fig. 7. (a) Disassembled and (b) assembled SynCore apparatus, and (c)-(e) additional equipment for performing the task.

apparatus are loaded. Combinations of 9 aldehydes and 18 amines (4 reactions for each student, a group of 20 students) are selected.

\section{Equipment}

The SynCore apparatus (modules for shaking, evaporation, and filtration) with 24 round-bottomed tubes (Figs. 7a, 7b). An ultrasonic bath (advisable) (Fig. 7d). Metal racks with various-height $3 \times 4$ ports (Figs. 7c and 7d). The low rack serves as a stand with can be placed as a whole into the ultrasonic bath (Figs. 7c and 7d). The high rack is used for filtering precipitates or passing mixtures through filters with silica beds (Fig. 7e). Glasses (60-100 ml) and pipettes.

\section{Acquired Skills}

In this task students get familiar with the SynCore apparatus which simultaneously fulfills the functions of stirring, shaking during extraction, filtration of 24 solutions from the drying agent, and analog of a rotor for evaporation from 24 vessels.

\section{PRACTICAL IMPLEMENTATION OF THE WORK}

Each student gets a variant of the task to obtain four target compounds IIE by reductive amination of one aldehyde IE with four different amines. Reagents and products are coded as above (Table 1). Reagents are loaded in a 1:1 ratio. The reducer is taken in a 3 -fold excess.

\section{Lesson 1. Reagent loading.}

(1) Each tube is provided with a label specifying the obtained variant, for example, F-1, F-2, F-3, F-4 (F is task variant and the figure is experiment number).

(2) Transfer $5 \mathrm{ml}$ of a DCM solution of aldehyde (15 mmol) and then $2 \mathrm{ml}$ of a DCM solution of corresponding amine $(15 \mathrm{mmol})$ to tubes with a pipette. Place the tubes into Syncore for agitation.

\section{Lesson 2. Introduction of reducer.}

(3) Add to each tube with a pipette $3 \mathrm{ml}$ of a DCM suspension of the $\mathrm{Na}\left[\mathrm{BH}(\mathrm{OAc})_{3}\right]$. Subject the tubes to ultrasound for 2-3 min for homogenization, then place them into SynCore and activate the shaking mode. The best results are reached within $2-3$ days $\left(\right.$ at $20^{\circ} \mathrm{C}$ ), but in rare cases, with poorly soluble compounds, the reaction may take up to 5 days. By the end of reaction the reaction mixtures acquire a gelatinous consistency.

Lesson 3. Treatment of reaction mixtures, drying of extracts. 


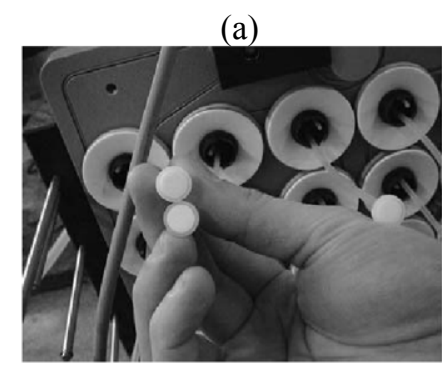

(d)

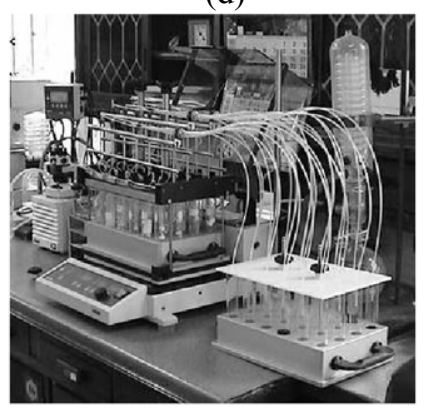

(b)

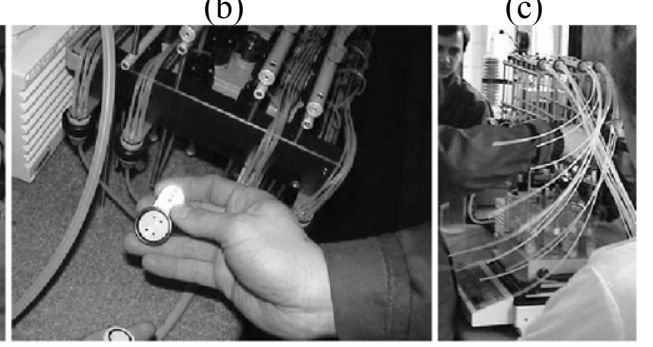

(e)

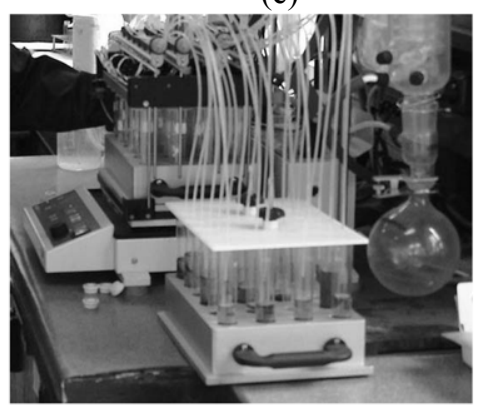

Fig. 8. Parallel filtering off of the drying agent in 24 samples.

(4) Add $20 \mathrm{ml}$ of $20 \%$ aqueous potassium carbonate to each tube. Place the tube into SynCore and shake for $1 \mathrm{~h}$. Over this period hydrogen evolution ceases completely. Prepare four empty with the same labels as on the reaction tubes.

(5) Withdraw with a pipette or syringe the lower (organic) layer and transfer it to an empty tube. The remaining aqueous layer extract two times with $10 \mathrm{ml}$ of DCM. Combine the organic layers.

(6) Add anhydrous $\mathrm{Na}_{2} \mathrm{SO}_{4}$ to the organic layer (the drying agent should be added so that it not fall on tube walls), shake the mixture for $30 \mathrm{~min}$, and leave overnight.

Lesson 4. Parallel filtration from drying agent and evaporation.

(7) Place the tubes into the reaction module of SynCore to filter off the drier. Place four pure tubes with labels to the receiver module in the strictly same order as in the reaction module. Perform parallel filtration and additional washing of the drier with a new solvent portion; to this end, attach the apparatus to a vacuum system.

The aim of this stage is to demonstrate to students an efficient system of parallel purification and washing of 24 reaction mixtures and filters from an inorganic dryer and from organic components (Fig. 8). Full washing of the system (tubes and filters) is reached within $40 \mathrm{~min}$ by successive passing of two portions of water $(2 \times 30 \mathrm{ml})$ and acetone $(2 \times 30 \mathrm{ml})$. Then the system is dried with a stream of nitrogen.

(8) Place the receiver module with collected filtrates into the SynCore rack, seal with a cover, attach to a vacuum pump (Buchi), and evaporate the solvent with shaking at $30-35^{\circ} \mathrm{C}$ and a vacuum of about $300 \mathrm{~mm}$ to prevent bumping.

\section{Lesson 5. Chromatography and purification.}

(9) Perform TCL of the obtained residue using as references the starting aldehyde and amine (eluent $\mathrm{CHCl}_{3} / \mathrm{MeOH}, 8: 1$, or $\mathrm{C}_{6} \mathrm{H}_{6} / \mathrm{EtOAc}, 2: 1$ ). If the starting aldehyde and/or amine are still present, perform chromatographic purification on a glass filter with silica bed (diameter $25 \mathrm{~mm}$, bed height $30 \mathrm{~mm}$ ), eluents chloroform and then $\mathrm{CHCl}_{3} / \mathrm{MeOH}, 20: 1$.

(10) The reductive amination product can be further purified by its precipitation as oxalate. To this end, add to a $\mathrm{CCl}_{4}$ solution of the product containing no starting amine admixture (or to a $\mathrm{CHCl}_{3}$ solution after chromatographic purification) an isopropanol solution of oxalic acid (15 mmol), and leave the solution until precipitate formation. Filter off the precipitate through a usual glass filter and dry in air. 


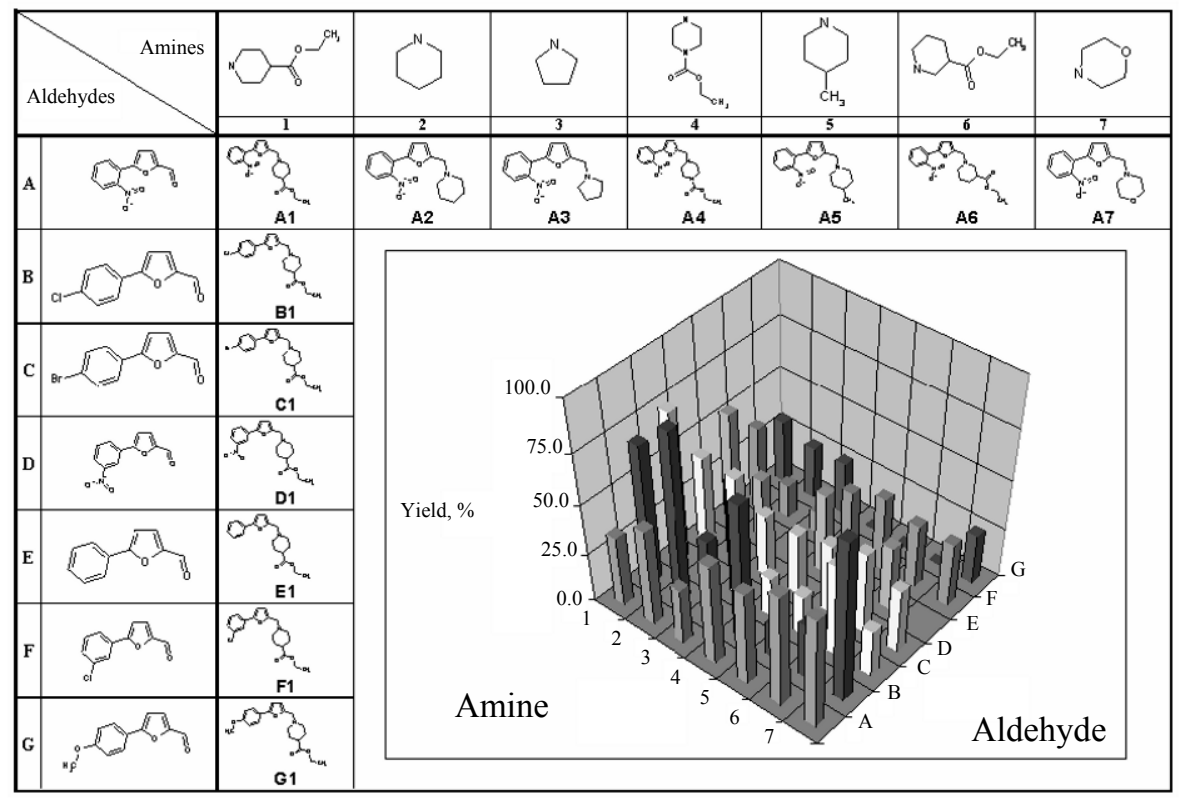

Fig. 9. Yields of products IIE.

\section{Lesson 6. Determination of product yields.}

(11) Prepare empty tubes and stick labels with product codes on them (the list of codes is available from the teacher). Weigh the empty tubes. Determine the weight of products and calculate their yield (Fig. 9). Provide one of the samples for ${ }^{1} \mathrm{H}$ NMR measurements.

The results of this work show that reductive amination in the 5-arylfurfural IE series is a reliable method of synthesis of substituted furfurylamines IIE. In this reaction, unlike the above two tasks, further purification is required in very rare cases. Therewith, the yields are generally quite high.

\section{REFERENCES}

1. Emerson, W.S., Org. Reactions, 1948, vol. 4, p. 174.

2. Lane, C.F., Synthesis, 1975, pp. 135.

3. Hutchins, R.O. and Hutchins, M.K., Comprehensive Organic Synthesis, Trost, B.M. and Fleming, I., Eds., Oxford: Pergamon, 1991, vol. 8, p. 25.

4. Baxter, E.W. and Reitz, A.B., Org. Reactions, 2002, vol. 59 , p. 1.

5. Henkel, T., Brunne, R.M., Mueller, H., and Reichel, F., Angew. Chem. Int. Ed., 1999, vol. 38, p. 643.
6. Abdel-Majid, A.F., Carson, K.G., Harris, B.D., Maryanoff, C.A., and Shah, R.D., J. Org. Chem., 1996, vol. 61, p. 3849.

7. Babaev, E., Belykh, E., Dlinnykh, I., Tkach, N., Bender, W., and Shoenenberger, G., Parallel Synthesis Reductive Amination of Aldehyde Group, Best@Buchi Synth., 2004, no. 34.

8. Geronikaki, A., Babaev, E., Dearden, J., et al., Bioorg. Med. Chem., 2004, vol. 12, p. 6559.

9. Mironov, M.A. and Babaev, E.V., Ross. Khim. Zh. (Zh. Ross. Khim. O-va im. D.I. Mendeleeva), 2009, vol. 53, no. 5, p. 133.

10. Saldabol, N.O., Popelis, Yu.Yu., and Slavinskaya, V.A., Khim. Geterotsikl. Soedin., 2001, vol. 8, p. 1021.

11 Tschitschibabin, A.E., Ber., 1926, vol. 59, p. 2048.

12. Babaev, E.V., Ross. Khim. Zh. (Zh. Ross. Khim. O-va im. D.I. Mendeleeva), 2009, vol. 53, no. 5, p. 96.

13. Denis, A. and Renou, C., Tetrahedron Lett., 2002, vol. 43, no. 23, p. 4171.

14. Alhambra, C., Castro, J., et al., Ibid., 2001, vol. 42, no. 38, p. 6675.

15. Bats, J.W., Frost, T.M., Hashmi, A., and Stephen, K., Acta Crystallogr., Sect. C: Cryst. Struct. Commun., 2001, vol. 57, no. 9, p. 1081. 